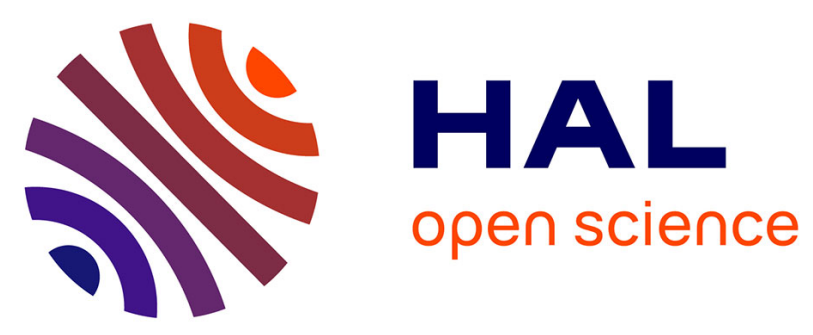

\title{
Towards a New Concept of Open Access Online Encyclopaedia: A Case Study from Croatia The Role of Encyclopaedias Today 1
}

\author{
Nataša Jermen, Zdenko Jecić
}

\section{- To cite this version:}

Nataša Jermen, Zdenko Jecić. Towards a New Concept of Open Access Online Encyclopaedia: A Case Study from Croatia The Role of Encyclopaedias Today 1. ELPUB 2020 24rd edition of the International Conference on Electronic Publishing, Apr 2020, Doha, Qatar. 10.4000/proceedings.elpub.2020.5 . hal-02544211

\section{HAL Id: hal-02544211 \\ https://hal.science/hal-02544211}

Submitted on 16 Apr 2020

HAL is a multi-disciplinary open access archive for the deposit and dissemination of scientific research documents, whether they are published or not. The documents may come from teaching and research institutions in France or abroad, or from public or private research centers.
L'archive ouverte pluridisciplinaire HAL, est destinée au dépôt et à la diffusion de documents scientifiques de niveau recherche, publiés ou non, émanant des établissements d'enseignement et de recherche français ou étrangers, des laboratoires publics ou privés. 


\title{
Towards a New Concept of Open Access Online Encyclopaedia : A Case Study from Croatia
}

\author{
Nataša Jermen and Zdenko Jecić
}

\section{The Role of Encyclopaedias Today}

1 The term encyclopaedia is generally thought of as indicating a device which systematically organises knowledge of a known, or knowable world (Featherstone and Venn, 5). Since the era of Enlightenment, traditional encyclopaedias have put forward a new approach to organisation and structuring of knowledge, and thus represent the forerunner of modern information system (Smolčić et al., 141). As reference works that contain a comprehensive summary of organised information, encyclopaedias have always played an important role in the process of acquiring knowledge). As such, they form an important part of the infrastructure for learning in institutions like schools, libraries and also universities (Sundin and Haider), as well as an indispensable tool for the beginning of a research process. The role of encyclopaedias in the agglomeration and dissemination of scientifically verified and consolidated information is even more underlined with the emergence of professionally edited open access online encyclopaedias, as they enable a systemic and reliable orientation within the everincreasing amount of data and information on the internet. Albeit Wikipedia (the "free online encyclopedia that anyone can edit") is having a huge impact on how a great many people gather information about the world (Fallis, 1662), professionally edited contemporary encyclopaedic projects have become places of easy access and exchange of trusted content, as well as information sources of networked and interconnected knowledge (Jermen and Jecić, 86). 


\section{Encyclopaedias in the Digital Realm - Towards a New Encyclopaedic Concept}

2 Digital technologies have challenged encyclopaedia publishers, which are nowadays primarily oriented towards publishing online encyclopaedias. The growth of Wikipedia as a user-generatedd online encyclopaedia and a source of competition has changed the encyclopaedia landscape profoundly and put considerable pressure on national encyclopaedias (Bentzen, 5). The gradual transition from traditional printed encyclopaedias towards collaborative open access online encyclopaedias, which has occurred during the last 20 years, generated significant changes in the foundation of encyclopaedistics. Until then encyclopaedic knowledge was available only to those who could afford to pay a high-price for multi-volume encyclopaedic editions. This has fundamentally changed in the digital age, which facilitated the distribution, accessibility and usage of encyclopaedic knowledge. By offering access to reliable and verified information, preferably in users' mother tongue, professionally edited open access online encyclopaedias could also play an important role in the struggle against misinformation provided by unreliable digital sources of knowledge. Namely, users need access to basic, reliable information in their mother tongue to be able to check facts and compare sources quickly and easily (Bentzen, 7). By acting as a connection between experts such as academic researchers on the one side and the average citizen, school pupil or university student on the other, online encyclopaedias should be the core of knowledge infrastructure of any modern society. Furthermore, the advent of digital technologies changed the epistemic configuration of encyclopaedias, transformed ways of preparing, organising and presenting encyclopaedic knowledge. Modern online encyclopaedias allow for continuous updating and expanding of the content, as well as for collaboration and cooperation between the content providers and users. They could serve as ideal platforms for internal and external knowledge networking by automatic linking across individual databases via machine-readable tagged data, which facilitates the generation of ontologies and inclusion into the semantic web (Jermen and Jecić, 89-90). This is opening up endless possibilities for interconnection of related content from different sources (e.g. libraries, museums, archives, social networks), which in turn is transforming online encyclopaedias into portals of knowledge. Encyclopaedic portals could represent a new concept of encyclopaedias in the digital realm, not only by serving as platforms for data networking and sharing but also by providing the essential encyclopaedic information for the diverse digital content. For example, currently, cultural object collections that refer to persons or items do not include comprehensive biographical or narrative information, which might provide relevant context to understand or interpret these artefacts. Researchers and interested public thus frequently lack access to existing information or have to bring together data from multiple sources. Encyclopaedic articles could become the connecting thread between miscellaneous digital content, thus transforming encyclopaedic portals into the multi-layered and comprehensive virtual collections.

3 Furthermore, thanks to the properties of the digital media and increasing connectivity, a closer collaboration between professionally edited online encyclopaedias across Europe (and beyond) is enabled, unlike with their traditional printed national counterparts. 


\section{Croatia's online encyclopaedias}

The Miroslav Krleža Institute of Lexicography from Croatia is a public institution (established in 1950), which is engaged in the activity of lexicography and encyclopaedistics, a professional as well the research discipline within the field of information and communication sciences in Croatia. In the course of its 70-year old history, the Institute, both a publishing house and a research institution, has published more than 400 volumes of general, national and specialised encyclopedias, lexicons, dictionaries and other issues, from nearly every field of human knowledge. They have contributed to the systematisation and presentation of specific research disciplines, social and cultural phenomena and have played a significant role in creation, maintenance and dissemination of scientifically verified public knowledge in Croatia.

In the past 20 years, the Institute has adjusted its development in response to paradigmatic global changes in encyclopaedistics. Namely, encyclopedia publishers have faced many challenges in the digital age, from the financial sustainability of projects and institutions to threats of their extinction and replacement by new, digital sources of knowledge.

6 Starting from 1990s the Institute has published several digital editions: in a copublishing effort with the publishing house Masmedia it has published The Lexicon of Economy on a CD-ROM (1995), with the co-publisher EURO-CAL (Form San Pedro, California) a pocket device World- traveller - 15 language translator (1998), and Croatia Tourist Guide on a CD-ROM (2000). Since the late 1990s, the appropriate steps have been taken to transform the process of editorial work from the traditional (i.e. paperbased) to the digital environment. During this time, a computerised editorial system was created in order to support the paper-based Croatian Encycloaedia (Jermen et al., 69).

However, the real efforts in the transition of the Institute's activity from paper-based to the digital environment started at the beginning of $21^{\text {st }}$ century. This process has been carried out in three principal directions: digitisation of archival editions, publishing permanently updated online general encyclopaedia and transformation of specialised encyclopedias to the encyclopaedic portals.

8 The first significant step towards Institute's digital transformation happened in 2009 when several, mostly specialised and commercially already exploited printed editions (published from 2003-05) were digitised and made freely available online in their original printed version via the platform Portal of Knowledge. The archival editions are being continuously digitised, and the priority is given to the editions of enduring or historical value or those that could be beneficial to the researchers of certain fields. The repository of freely accessible digitised archival Institute's editions (Portal of Knowledge; http://enciklopedija.lzmk.hr/), currently offers access to 9 editions containing approximately 120000 encyclopaedic articles.

9 The key step in the Institute's digital transformation was the launch of the online edition of the Croatian encyclopaedia (https://www.enciklopedija.hr/), general encyclopaedia intended for the general public, in 2013. It is based on the printed edition published in 11 volumes from 1999- 2009 and authored by over 1000 external experts. At present, it is fully compiled and published in the digital form, and issuing of 
printed volumes is not foreseen. It contains more than 70000 encyclopaedic articles that are being permanently updated and expanded, and also newly written articles are added to the online edition. The Croatian encyclopaedia has been established as one of the principal digital reference sources in the Croatian language, with approximately 40 000 daily visits, thus fulfiling its main task to provide reliable and verified information to users in their mother tongue.

The third important part of the Institute's activity in the digital environment is being developed within big national cultural and research encyclopaedic projects, that involve numerous external collaborators and significant financial means. Resulting in long-term comprehensive specialised encyclopaedic works they are characterised by orientation towards a limited circle of experts, researchers or the interested public, and also by the expectation (at least from the part of users) that the final outcome of the project will be a traditional, printed encyclopaedia. This involves projects that are being conceived in parallel as printed and online editions, as is the case with Croatian Biographical Lexicon and Croatian Encyclopaedia of Technology. The Croatian Biographical Lexicon (http://hbl.lzmk.hr/) elaborates famous Croatian personalities, which are being published in alphabetical order since the 1980 s (at the moment the $9^{\text {th }}$ volume is being prepared). Since 2009 the articles are published both in print and online and since 2015 a number of biographies are available online first.

11 Taking a step further, a new type of encyclopaedic projects is being developed, with the Croatian Encyclopaedia of Technology as the most representative example. Dealing with the national technological heritage, it was initiated in 2014 and is carried out in collaboration with relevant institutions and experts across the wide technological community in Croatia. This Encyclopaedia is an innovative encyclopaedic project in Croatia being the first encyclopaedia conceived primarily as a web-based edition. All written and edited encyclopaedic articles are published on the Encyclopaedia's web pages (Portal of the Croatian Technology Heritage; https://tehnika.lzmk.hr/), freely available to the general public, thus enabling the collaborative approach and interventions of users who can suggest improvements, updates and the correction of possible errors. Subsequently, the printed edition is being prepared with the plan of publishing four volumes, each of which will be devoted to specific fields of technology area. Thus, the users are continuously in contact with the project's progress, and the results are available immediately, which is not the case in traditional, paper-based enyclopaedistics. In addition, the expectations of certain user groups (especially older ones) are met, since they are provided with the printed edition.

In line with our comprehension of the new encyclopaedic concept, the Encyclopaedia (i.e the Portal) provides rich content-related data at the end of each article that are supplemented with various sections, primarily aimed at linking with external sources to enable further exploration of a topic (other internet sources, bibliographic references, digital data about the physical artefacts accessible in public spaces etc.).

13 The plan is to introduce new sections into the Portal and further develop its functionality, which will serve as the basis for interoperability with digital repositories of other cultural and research institutions. This is already ensured by extracting a rich set of metadata presented in infoboxes, which are serving as a brief content overview, enabling multiple queries to the database and semantic linking of the content with various institutions in Croatia as well as abroad, thus turning the Portal into a sort of repository of the Croatian technology heritage. 
Open access online Croatian Encyclopaedia of Technology, i.e. Portal of Croatian Technology Heritage, represents a step forward towards the new encyclopaedic concept, serving not only as a reliable information source, but also as the knowledge networking and research platform, and as such it gives possible directions for the development of professional online encyclopaedias.

Altogether, freely accessible Institute's collections of digitised and digital encyclopaedic editions comprise of approximately 250000 articles, which in 2019 had around 4200000 million users and 12000000 pageviews. The Institute's goal in the forthcoming years is to upgrade its digital repository of encyclopedic content with the purpose of developing public knowledge of the highest scientific relevance.

\section{Collaborative efforts of the Miroslav Krleža Institute of Lexicography}

Publicly available online encyclopedic content, that is the repository of encyclopaedic knowledge which the Miroslav Krleža Institute of Lexicography is being developing, enables the linking to the digital data and collections of other research and cultural institutions. In such a way, the Institute helps reinforce digital research, didactic and cultural infrastructure, contributes to dissemination and popularisation of the results of scientific research and also supports the open science initiative.

So far, the Institute has collaborated in several inter-institutional and multidisciplinary collaborative projects aimed at developing research and cultural infrastructure. Znameniti.hr (http://znameniti.hr/), the project aimed at building a thematic portal containing digital material on the leaders of Croatian culture, science, arts and public life from different collection/repositories, is being performed since 2016 in collaboration of eight Croatian research and cultural institutions. As the result of an European project funded by the DARIAH-ERIC in 2017 and 2018, the regional cooperation was established, as well as the digital platform EminentPeople (https:// eminentpeople.eu/), that enables search and access to digitised works of famous persons from culture, science, art and public life who have been active in Bosnia and Herzegovina, Croatia, and Slovenia. In 2018 the Institute joined the consortium of the Time Machine project (https://www.timemachine.eu/), a large-scale research initiative aiming to develop the big data of the past, a huge distributed digital information system mapping European social, cultural, and geographical evolution through time, which brings together more than 300 organisations from 34 countries.

18 The aim of this paper is also to stress out a range of initiatives seeking to build connections across individual European, as well as North American national encyclopaedias. One such initiative was the international conference Encyclopaedias Around Table organised by the Miroslav Krleža Institute of Lexicography and the Bulgarian encyclopaedia, which was held in Zagreb in 2005. The conference gathered representatives of 6 encylopaedia publishers operating in "non-global" or "small" languages (from Croatia, Bulgaria, Catalonia, Ireland, Estonia and Poland) who presented their past and ongoing projects and discussed the future of encyclopaedias in the digital media, as well as the possibilities for collaboration.

19 Another initiative launched in 2008 (by Enciclopèdia Catalana from Barcelona) aspired to create a European macro-encyclopaedia by linking national corpora of open-access 
encyclopaedias, but due to a number of reasons didn't get to a release stage. It initially gathered 16 editorial houses from 12 European countries with the intention to construct a virtual space, freely accessible, containing the European Encyclopaedia, or Europedia. As an instrument that makes possible an overall view of the whole of Europe and of its different cultures, while preserving the different national visions, it was meant to be an indispensable tool for improving the reciprocal knowledge of all Europeans and strengthening their common identity. It was also an attempt to match Wikipedia, with quality, free access and availability, participation (crowdsourcing), and also the size.

The ongoing activities involve the establishment of the association of European and North American encyclopaedia publishers and the development of collaborative projects with the main purpose of alleviating current European heterogeneous online encyclopaedia landscape and providing a counteraction to the 'fake news' phenomenon. The transnational partnership between European and North American encyclopaedia publishers aims to tackle common challenges - e.g. providing free access to sources of trustworthy, general knowledge in the post-fact era - whilst promoting Europe's cultural and linguistic diversity.

In 2018 the Institute (as the lead partner) joined forces with the Great Norwegian Encyclopedia (SNL), the National Library of Latvia, and the Montenegrin Academy of Sciences and Arts, and applied for the 'EEA and Norway Grants Fund for Regional Cooperation' with the project proposal Stronger together: Building visible and sustainable online encyclopaedias for free access to reliable knowledge in an era of post-truth and propaganda (the results haven't been announced yet). The project's aim is to enhance the participants with the institutional and technical capacity needed to meet long-term challenges in a sustainable way. A core part of the project is establishing a shared publishing platform, based on the SNL's purpose-made publishing software (Bolstad and Pettersen, 161-162), which will create the basis for editorial cooperation and shared institutional capacity building. The intention is to make this new and improved publishing platform available to additional non-commercial partners outside the consortium.

The role of encyclopedias in the digital age was discussed at the first European Encyclopedia Conference in Brussels in 2019, organised by the Great Norwegian Encyclopedia, the European Parliamentary Research Service, and the Mission of Norway to the European Union, which brought together editors and publishers of general encyclopedias from 17 European and North American countries. The goal of the conference was to share experiences about the current state and functioning model of national encyclopedias and define possible areas of cooperation. The conclusion was that by fulfilling their basic goal - offering access to reliable and verified information of general interest in the user's mother tongue - encyclopedias could play an important role in the struggle against misinformation, fake news, and propaganda. Public access to basic, reliable background information about history, culture, society and politics is an essential part of our societies' complex knowledge ecosystem (Bentzen, 1). 


\section{BIBLIOGRAPHY}

Bentzen, Naja. Europe's Online Encyclopaedias: Equal Access to Knowledge of General Interest in a PostTruth Era. European Parliamentary Research Service, 2018. doi:10.2861/002977.

Bolstad, Erik, and Stig Arild Pettersen. "How to Build an Encyclopedia for the $21^{\text {st }}$ Century: Lessons Learned from The Great Norwegian Encyclopedia.” Studia Lexicographica, vol. 13, no. 24, 2019, pp. 153-71. doi:10.33604/sl.13.24.5.

Fallis, Don. "Toward an Epistemology of Wikipedia." Journal of the American Society for Information Science and Technology, vol. 59, no. 10, Aug. 2008, pp. 1662-74. doi:10.1002/asi.20870.

Featherstone, Mike, and Couze Venn. "Problematizing Global Knowledge and the New Encyclopaedia Project: An Introduction.” Theory, Culture \& Society, vol. 23, no. 2-3, May 2006, pp. 1-20. doi:10.1177/0263276406065779.

Jermen, Nataša, and Zdenko Jecić. “Science Networking: Role of Online Encyclopaedias.” Circumscribere: International Journal for the History of Science, vol. 21, June 2018, p. 84-95. doi: 10.23925/1980-7651.2018v21;p84-95.

Jermen, Nataša, et al. "Lexicography and Encyclopaedistics in the Digital Environment." INFuture2015: E-Institutions - Openness, Accessibility, and Preservation, Faculty of Humanities and Social Sciences, University of Zagreb, 2015, pp. 65-76. doi:10.17234/INFUTURE.2015.9.

Smolčić, Ivan, et al. "Epistemological Value of Contemporary Encyclopedic Projects." INFuture2017: Integrating ICT in Society, Faculty of Humanities and Social Sciences, University of Zagreb, 2017, pp. 141-49. doi:10.17234/INFUTURE.2017.15.

Sundin, Olof, and Jutta Haider. "The Networked Life of Professional Encyclopaedias: Quantification, Tradition, and Trustworthiness.” First Monday, vol. 18, no. 6, June 2013. doi: 10.5210/fm.v18i6.4383.

\section{ABSTRACTS}

Professionally edited open access online encyclopaedias enable a systemic and reliable orientation within the ever-increasing amount of data and information on the Internet. Providing access to scientifically verified information, they represent an important part of the research and didactic infrastructure.

This paper demonstrates the activities of Croatia's Miroslav Krleža Institute of Lexicography aimed at exploring the new encyclopaedic concept in the digital age. The Institute's digital transformation is shown, which involves the digitisation and online publishing of archival editions, publishing of the permanently updated online general encyclopaedia, and the transformation of specialised encyclopedias to the encyclopaedic portals. Encyclopaedic portals could represent a new concept of encyclopaedias in the digital realm by serving as platforms for data networking and sharing, a sort of 'junction points' that connect diverse digital content on a specific topic.

Institute's publicly available repository of encyclopaedic knowledge enables the linking to the digital data and collections of other research and cultural institutions; therefore the collaborative projects aimed at reinforcing digital research and cultural infrastructure will be described.

Thanks to the properties of the digital media and increasing connectivity, a closer collaboration 
between professionally edited online encyclopaedias across Europe (and beyond) is enabled. This paper elaborates a range of initiatives seeking to build connections across individual European and North American national encyclopaedias, focusing on the role that Croatian encyclopaedistics plays in this endeavour.

INDEX

Keywords: online encyclopedia, open access, encyclopaedic portal, knowledge networking platform, interoperability

\section{AUTHORS}

\section{NATAŠA JERMEN}

The Miroslav Krleža Institute of Lexicography, Zagreb, Croatia e-mail: natasa.jermen@lzmk.hr (corresponding author)

ZDENKO JECIĆ

The Miroslav Krleža Institute of Lexicography, Zagreb, Croatia 